\title{
AFET ANTROPOLOJISİ
}

\section{DISASTER ANTHROPOLOGY}

DOI: $10.17755 /$ esosder.89650

\section{Nehir VAROL ${ }^{1}$ Timur GÜLTEKİN ${ }^{2}$}

\section{$\ddot{O} \mathbf{z}$}

Afet, ekonomik ve sosyal kayıplara neden olan, sosyal hayatı kesintiye uğratan ve ani olarak gelişen olaylar olarak tanımlanır. Çok disiplinli bir yaklaşımı gerektiren, afet çalışmaları hem teknik hem de sosyal bilimler bakış açısı ile yürütülmelidir. Bu nedenle, insanı kültürel, toplumsal ve biyolojik çeşitliliği içinde anlamaya, insanların başlangıcından beri çeşitli koşullara nasıl uyarlandığını, bu uyarlanma biçimlerinin nasıl gelişip değiştiğini, çeşitli küresel olayların bu uyarlanmaları nasıl dönüştürdüğünü görmeye ve göstermeye çalışan Antropoloji bilimi, afet yönetim sistemi içerisinde mutlaka yer edinmelidir.

Yabancı kaynaklarda afet antropolojisine ilişkin çalışmaları görmek mümkündür. Bazı ülkelerde, üniversitelerde, afet antropolojisi ders olarak da okutulmaktadır. Ancak Afet Antropolojisi kavramı, afet risk yönetimi çalışmalarında genel anlamda henüz yerleşmiş bir kavram değildir. Bu çalışmanın amacı, Afet Antropolojisi kavramının tanıtılması ve yaygınlaştırılmasını sağlamak, antropolojinin afet çalışmalarında ve afet risk yönetimi sürecine nasıl katkı sağlayabileceğini tartışmaktır.

Anahtar Kelimeler: Afet Antropolojisi, Afet Risk Yönetimi

\begin{abstract}
A disaster is a sudden, calamitous event that seriously disrupts the functioning of a community or society and causes human, economic or social losses. Disaster management studies require a multidisciplinary approach and it should be conducted with both technical and social science perspective. Therefore, Anthropology science which has tried to understand of human in cultural, social perspective and determined understanding of biodiversity, how people adapted to various conditions since the beginning, and shows that how to adapted to changes and various conditions. Thus, Anthropolgy science has to find a place necessarily in disaster management system.

Even, we can see Disaster Anthropology as a course in some countries, universities programs. But terminology of the Disaster Anthropology is not a common concept in disaster risk management studies in many countries. The aim of this study is the introduction of the Disaster Anthropology terminology and discuss how it can contribute to disaster risk management processes.
\end{abstract}

Keywords: Disaster Antropology, Disaster Risk Management

\footnotetext{
${ }^{1}$ Yrd.Doç.Dr. Ankara Üniversitesi Beypazarı Meslek Yüksekokulu - Acil Durum ve Afet Yönetimi Bölüm Başkanı, nehir.varol@gmail.com

${ }^{2}$ Prof.Dr. Ankara Üniversitesi Dil ve Tarih Coğrafya Fakültesi Antropoloji Bölümü, timur.gultekin@ankara.edu.tr
} 


\section{Giriş}

Afet, bir toplumu ya da çevreyi olumsuz olarak etkileyen, aniden gelişen, doğal ya da insan kaynaklı olaylardır. Doğal ya da teknolojik tehlike risk ile birleştiğinde yıkıcı afetler meydana gelebilir. Dolayısıyla, öncelikle afet risk yönetiminde temel kavramlar olan tehlike ve risk kavramını tanımlamak gerekir. İnsanlar için olumsuz etkiler doğurması mümkün olan doğal, teknolojik ve insan kökenli olayların tümü tehlike olarak tanımlanabilir. Risk ise, gelecekteki belirli bir zaman içinde belirli bir tehlikenin bu tehlikeye maruz olan değerler veya tehlike altındaki unsurları bunların zarar veya hasar görebilirliklerine bağlı olarak verebileceği zararları ifade eder.

Bu kavram tanımları 1şı̆̆ında Afet Yönetimi şu şekilde tanımlanabilir;

Afet yönetimi, afetlerin önlenmesi ve zararlarının azaltılabilmesi için afet öncesi, afet sırası ve afet sonrasında yapılması gereken idari yasal ve teknik çalışmaları belirleyen ve uygulamaya aktaran, bir olayla karşılaşıldığında ise bir uygulama yapabilmeyi sağlayan ve her olaydan elde edilen derslerin 1şı̆̆ında mevcut sistemi geliştiren bir yönetim biçimi veya uzmanlık alanı olarak tanımlanabilir (Özey,2006). Kökenleri ve gelişim hızları ne olursa olsun tüm afet olayları ile ilgili faaliyetler ve afet yönetim döngüsü, 5 ana safhaya ayrilabilir. Bunlar: 1- Zarar azaltma 2- Önceden hazırlık 3- Kurtarma ve ilk yardım 4- İyileştirme ve 5- Yeniden inşa safhalarıdır.

$\mathrm{Bu}$ süreçler zarfında, toplumda afetlere karşı direnç az ise, yani zarar görebilirlilik /kırılganlık olduğu zaman, afet oluşumu ve afetlerden etkilenme kaçınılmaz olur. Olayın yeri, yapısı, sosyopolitik koşullar ve toplumun kültürüne bağlı olarak zarar görme derecesi artabilir ya da azalabilir. Genel anlamda, zarar görebilirlik kavramını, "Potansiyel bir olayın meydana gelmesiyle toplumun uğrayabileceği olası ölüm, yaralanma, hasar, yıkım ve kayıp ve zararların bir ölçütü” şeklinde ifade edebiliriz. Bir başka ifade ile zarar görebilirlik, toplumun baş edebilme kapasitesinin tersidir.

Afet ve Acil Durumlar öncesi, sırası ve sonrasında teknik ekipler (jeoloji, inşaat, çevre mühendisleri, şehir plancılar vs.) afetin olası fiziksel yıkımını en aza indirmek ve afet sonrasında çevrenin yeniden düzenlenmesi, güvenli bir şekilde aynı yerde ya da başka yerde yeniden inşasıyla ilgilenirler. Ancak sosyal bilimciler, afet olduğunda insanların reaksiyonlarını inceler ve bu reaksiyonların afet oluşumuna ve önlenmesine etkisi ve toplumun kültürel yapısı ile ilişkisini değerlendirirler.

Antropolojik çalışmaları temel anlamda, sosyal antropoloji ve fiziki antropoloji olarak sınıflandırmak mümkündür. Sosyal antropoloji, Afet Risk Yönetimi döngüsünün her aşamasında, fiziki antropoloji ise özellikle afet sonrası döneminde fayda sağlayacaktır. Afetlerin tarihsel episodu, toplumların davranış özellikleri afet antropolojisi çalışmalarının temelini oluşturmaktadır. Afetin kültürel farklılıkları afet ve acil durumlarda toplumun davranışlarını belirlemektedir. $\mathrm{Bu}$ davranışlar bazen afete karşı direnci artırırken, bazen de kırılganlıkları artırabilmektedir.

Afet Antropolojisi kavramı henüz yaygın bir kavram olmamasına rağmen, 1950'lerde antropologların afet çalışmaları alanına girdiğini görmekteyiz. Toplumun antropolojik yapısı ve kültürü özellikle insan kökenli afetlerin oluşum sıklığını da etkilemektedir. Farkındalık yaratmış ve afet kültürünü yerleştirmiş toplumlarda insan kökenli afetlerin yaşanma sıklığı da azalmaktadır. Afet Antropolojisi çalışmaları ve sosyal boyutlu çalışmaların afet zararlarının azaltılması çalışmalarına entegrasyonu, sürdürülebilir başarılı bir afet risk yönetimi için gereklidir.

Afet çalışmalarında başarı çok disiplinli bir yaklaşımı gerektirmektedir. Teknik ve sosyal boyutu vardır. Coğrafya, meteoroloji, mühendislik, kültür, politika, çevre, ve ekonomi bu döngünün içerisnde yer alır. Genellikle sosyal boyut çalışmalarda ihmal edilir ya da ikinci planda değerlendirilir. $\mathrm{Bu}$ tarz yaklaşımlar afet risk yönetiminde aksaklıklar meydana getirecektir. Gerek uluslararası gerekse ulusal düzeydeki yardım çalışmalarında da sosyolojik, antropolojik, psikolojik ve kültürel yaklaşımlar göz ardı edilmemelidir. Afetler bütün bir ekolojik sistemin parçasıdır. Nüfus 
ve potansiyel yıkıcı etkileri kapsayan hem doğal hem de artificial elemanları içerir (Anthony and Hoffman, ). Bu elemanlar toplumsal kırılganlık olduğu zaman yıkıcı hale gelebilirler.

Tehlike ve risklerin belirlenmesi genellikle teknik çalışmaları gerektirse de, afet risk yönetimi süreçlerine sosyolojik, kültürel, psikolojik çalışmaları katmak, başarıyı şüphesiz artıracaktır.

\section{Kültürel Yapı Ve Zarar Görebilirlik}

İnsanın yaşadığı habitattaki değişimler bazen kendisi için tehlike oluşturabilir ve afete de dönüşebilir. Olay, büyüklüğü nedeniyle değil, ona karşı kırılgan ve zarar görebilir olduğumuz için bir afete dönüşür (Soucaille, 2008). Doğa olaylarının önlenemeyeceğinin bilincine varan insanoğlu, bu tür olayları en az zararla atlatabilmenin yollarını aramıştır. Bu süreçte afet zararlarını azaltma stratejileri önem kazanmıştır. Afetlerin hayat döngüsü içerisindeki etkisi, afet öncesi toplumların yaşam tarzına bağlı olarak oluşan zarar görebilirlikleri ve afetler sonrası insanın o koşullarla başa çıkma yetisi, afet risk yönetiminde belirleyici unsurlardır. Bu aşamada toplum kültürü ve antropolojisi toplumların afete hazırlık, daha sonrasında yardım, kurtarma ve yeniden hayata ve normale dönme sürecinde etkili olmaktadır. Toplumlara göre bu süreçler daha kırılgan ya da daha başarılı bir şekilde tamamlanmaktadır. Afet öncesinde veya sırasında toplumun olaya karşı verdiği reaksiyon toplumun geçmişine, kültürüne ve sosyolojisine göre farklılıklar göstermektedir.

İnsanoğlu çok farklı çevre koşullarında hayatlarını sürdürmektedir. Bu koşullar insanların kültürel ve sosyal yapısını etkilemekte ve genel karakterini belirlemektedir. Toplumların sosyal, kültürel, politik ve ekonomik özellikleri, onların afetler karşısında verdikleri tepkileri, başa çıkma kapasitelerini etkilemektedir. Antropoloji çalışmaları, bireylerin afetlere karşı kırılganlıklarının ya da başa çıkabilme kapasitesinin etkilenebilirliğinin değerlendirilmesi açısından da oldukça önemlidir.

Afet riski, literatürde şöyle formüle edilir.

\section{Afet Riski $=$ Tehlike * Kirllganlık}

Bu formülü, Blaikieand Al. (1994), aşağıdaki şekille detaylandırmıştır. Tehlikenin, kültürel ve sosyolojik yapı, eğitimsizlik, hızlı nüfus artışı, çarpık kentleşme, orman örtüsünün tahribi vb. etkenler ile birleştiğinde maalesef depremler, seller, heyelanlar gibi birçok afetin oluşmasına ve toplumun bu afetler karşısında zarar görmesine neden olmaktadır.

\section{Şekil 2.1.: Afetlerde kirllganlık faktörleri, Blaikieand Al. (1994),}

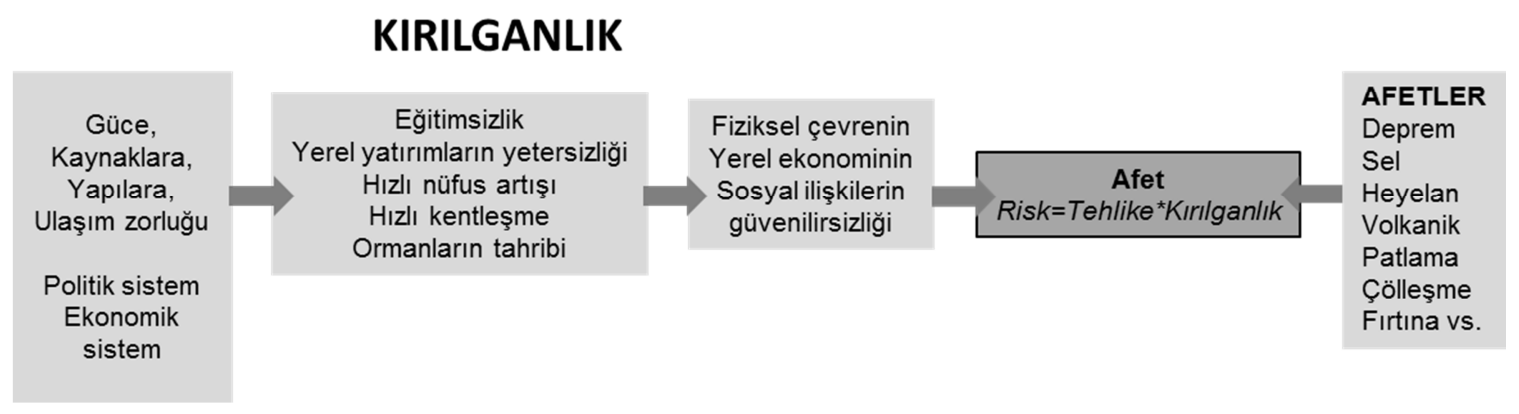

İnsanlar geçmişten günümüze kendi isteği doğrultusunda doğal yaşamda bazı uygulamalara gitmiştir. Özellikle, ticaret ve yatırım adı altında büyük fabrikalar, yazlık konutlar ya da büyük turizm tesisleri en güzel kıyılarda inşa edilirken ormanlar kesilmekte, tarım alanları yok edilmekte, yetersiz yüzey suları nedeniyle aşırı su gereksinimi yeraltı sularından sağlanmakta ve böylece 
düzeyi düşürülmekte, sular kirlenirken su kalitesi bozulmaktadır. Yaban hayatı ve ekolojik dengeler açısından doğal haliyle bırakılması gereken kıyılarda büyük inşaatlar yapılırken, yavaş gelişebilecek afetlerin yanı sıra, tusinami ve deprem gibi ani oluşabilecek afetlere de maruz kalabilmektedir. Burada görüldüğ̈ gibi insan kendi eliyle doğayı değiştirerek afetlerin oluşumunu da tetiklemektedir (Ersoy 2013). Antropolojik açıdan olaya baktığımızda insanoğlunun doğadaki bu uygulamaları antroposantrik dünya görüşünün halen hakim olduğunu göstermektedir.

İnsanoğlu, kendine özgü bu kültürü sayesinde dünyanın her yerinde yaşamını sürdürebilmektedir. İnsanın dünyamızdaki farklı ekolojik koşullara karşı önlem almadan bu şekildeki hızlı ve kontrolsüz yayılımı olası afetlerdeki kayıpları artırmakta ve doğa olaylarının bir trajediye dönüşmesine neden olmaktadır.

Anthony Oliver Smith (1996)' ya göre bu sosyal kırılganlık, yaşam tarzının iyi yönde değiştirilmesi, fiziksel çevreye adaptasyonun kuvvetlendirilmesi ve geleneksel bilginin kullanımı ile azaltılabilir. Afet Antropolojisi yaklaşımında, afet politikaları ve uygulamalarında yerel kültür dikkate alınmalıdır. Bazen afetin meydana geldiği toplumun özellikleri ve kurumların yapısı afetin yıkıcı etkisinden çok daha çok zarar verebilir hale gelmektedir. (Faas and Barrios 2015). Kırılganlıkların ve risklerin çokluğu afetlere karşı direnci ve başa çıkmayı zayıflatacak unsurlardır (Drabek, 1994).

Sosyal sistem içerisinde, kültür etkisi bazı toplumları diğer toplumlara göre afetler karşısında daha zarar görebilir hale getirebilmektedir. Etnik azınlıklar, dini gruplar, bazı cinsiyetler ve bazı meslek alanlarındaki gruplar afetlerden daha fazla etkilenebilmektedir (Torry 1979, Zaman 1989, Haque and Zaman 1993, Bankoff 2003).

Örneğin 1976 Guatemala depreminde, fakir insanların yaşadığı bölgeler diğer bölgelere göre orantısız bir şekilde çok fazla etkilenmiştir (Blaikie et al. 1994). Depreme oldukça dayanıksız yapılarda yaşayan bu kesimde can kayıpları yaşanmıştır. Hatta bu belirgin fark nedeniyle, bu depreme için sınıf depremi (classquake) tabiri kullanılmıştır. Ekonomik yapı dışında, toplumsal cinsiyet de zarar görebilirlik açısından etkili olmuştur. Ayrıca toplumun kültürüne ve sosyal yapısına bağlı olarak genelde kadınlar ve çocuklar afetlerden daha çok etkilenen gruplar olarak görülmektedir. Bu örnek afet öncesi dönemde toplumların kültürü, sosyo-ekonomik yapısının, zarar görebilirliğe etkisini göstermektedir. Ayrıca afet sırası ve sonrasında da kırılganlığ etkileyen bir diğer faktör, toplumun inanç yapısıdır. Antropologlar bir toplumun inanç yapısının afetler sırasında ve sonrasında afetlere karşı psikolojik açıdan nasıl direnç sağladığını irdelemişlerdir (Lindstrom 1993, Maida 1996). Afet sonrası travmanın daha kolay ve kısa sürede atlatılmasında, inançsal özelliklerin faydası test edilmiştir.

Antropologlar ayrıca afetlerin, yaşandığı ülkenin siyasi dengelerini ve örgütlenmeleri nasıl değiştirdiğini de gözlemlerler (Chairetakis 1991, Button 1992). 1999 yılında yaşanan Marmara Depreminden sonra siyasi ve ekonomik yapıda değişiklikler yaşanması bu sürece örnek oluşturabilir. Marmara depremleri sonrasında, ülkemizde afet yönetim sisteminde değişikliğe gidilmiş, teşkilatlar yeniden yapılandırılmıştır.

Hemen hemen her gün dünyanın farklı yerlerinde, farklı boyutlarda afet olayları yaşanmaktadır. Ancak bu afetlerin sonuçları gerçekleştiği yere ve topluma göre değişim göstermektedir. Bir tehlikenin afete dönüşmesi sadece tehlikenin büyüklüğü ve yoğunluğu ile alakalı değil, sosyolojik ve psikolojik kırılganlıklarımızla da ilişkilidir (Soucaille, 2008). Aynı büyüklükteki afet, 2 farklı ülkede farklı zararlara yol açabilmektedir. Bu durum o toplumun farkındalığı, afetlere karş1 kırılganlığı ve başa çıkabilme kapasitesiyle doğrudan alakalıdır. Afetlerin zararlarının azaltılması noktasında yapılan, Afet Risk Yönetimi çalışmalarının başarısı, toplumun kültürüne, yaşanılan 
olaylardan çıkardığı derslere, bu tür olaylar karşında verdiği tepkiye, kültürel ve sosyolojik yapısına bağlıdır. Dolayısıyla afetler karşısında insanların davranışları ve bakış açıları, afet ve acil durumlardan az ya da daha çok etkilenmelerine neden olur. Sonuç olarak afet antropolojisi de; din, ekonomik yapı, politika, kurumsal yapıların farklılıklarının üzerinde odaklanır. Yerel ve merkezi kurumların afetlerin etkilerinin azaltılması noktasında sosyal boyutta nasıl çalışacağı ve bu çalışmaların gelenekler, cinsiyet, etnisite ve sosyo-ekonomik statülerden kaynaklanan farklı başa çıkma durumlarının neler olabileceğini inceler. Planlama yaparken, geçmiş olaylara nasıl reaksiyon gösterildiği ve olayla nasıl başa çıkıldığı, hangi stratejilerin izlendiği, geleneksel bilginin ve alışkanlıkların başa çıkma sürecinde nasıl kullanıldı̆̆ını irdeler. Yaşam tarzının değişimi, sosyal alışkanlıkların düzenlenmesi, fiziksel çevreye adaptasyon ve geleneksel bilginin kullanımı sosyal kırılganlıkları azaltabilir.

\section{Sonuç}

Toplumların, nüfus yoğunluğu, politik yapısı, inançları, gelenek ve görenekleri afetlere hazırlanma kapasitelerini ve afetler sırasında verdikleri reaksiyonları ve davranışları etkilemektedir. $\mathrm{Bu}$ bağlamda, Antropologlar; toplumların içsel sosyal ve ekonomik yapısı ve dinamikleri, toplumların dışsal sosyal ve çevresel ilişkileri, toplumların doğaya adaptasyonu, tüm bu özelliklerin afetlerin zararlarının azaltılması konusunda uygulanabilirliği konusunda çalışmalar yürütebilirler ve afet risk yönetimi çalışmalarına katkıda bulunabilirler.

Şimdiye kadar ülkemizdeki çalışmalar; genelde insan ekolojisi ve bu bağlamda afetlerin ekoloji ve insan yaşamı üzerindeki etkileri üzerindedir. Afet antropolojisi ile ilgili ileriki yıllarda;

1-İnsanlık tarihindeki afetler ve bunun toplumları kültür ve yaşam şekilleriyle ilişkilendirilmesi.

2 - İnsan kökenli afetler hakkında bilgi verilmesi.

3-Geçmişte meydana gelmiş olan afetlerden elde ettiğimiz bilgi kazanımları ve deneyimlerin neler olduğu ve oluşabilecek afetlerde bu deneyimlerden nasıl faydalanılacağı.

4- Afetlerin insan doğasına etkileri

5- Afetlerde insanların fizyolojik sınırları

6- Afetlere karşı geliştirilecek bakış açısı ve kabullenme

7- Dünyanın farklı coğrafyalarında meydana gelmiş olan afetlerin analizi ve toplum üzerindeki etkilerinin sunulması gibi konularında çalışmalar yoğunlaştırılabilir.

Yukarıda bahsedilen çalışmaların gerçekleşebilmesi için afetler konusunda eğitimli, analiz yapabilen ve çözümler üretebilen afet antropologlarının ortaya çıkması gerekir. Afet Yönetim sürecinde antropologların da görevlendirilmesi, genel kuralların yanı sıra topluma özgü formüller gündeme getirecek ve zarar azaltma çalışmalarının başarısını artıracaktır.

Afetlere, sosyal, kültürel, politik, ekonomik ve çevresel ilişkileri içeren geniş bir pencereden bakmak, bu özelliklerin afetlerin şiddetini nasıl etkileyebileceğini irdelemek, afet öncesi dönemde yapılacak risk çalışmalarının başarısına tartışmasız katkı sağlayacaktır. Afet sonrası dönemde de toplumun özelliklerine uygun çalışmalar yürütmek afetlerle başa çıkma kapasitesini artıracaktır. 


\section{Kaynakça}

Akin G., (2007). Küresel Çevre Sorunları, Cumhuriyet Üniversitesi Sosyal Bilimler Dergisi, 31(1), 43-54.

Bankoff G., (2003). Vulnerability as a Measure of Change in Society, International Journal of Mass Emergencies and Disasters, Vol. 21, No. 2, pp. 5-30.

Bates, D.G., (2009). 21. Yüzyılda Kültürel Antropoloji, İnsanın Doğadaki Yeri (Çev.Ed. Aydin S, Altuntek S, Altınok EB, Demirakın, N.I., Ersoy E., Karabulut N., Özbudun S., Şafak B.) İstanbul Bilgi Üniversitesi Yayınları 265, İstanbul.

Blaikie P., T. Cannon, I., Davis, and B. Wisner., (1994). At Risk: Natural Hazards, People's

Button, G. 1992. Social Conflict and Emergent Groups in a Technological Disaster: the Homer Area Community and the Exxon-Valdez Oil Spill. Unpublished Ph.D. thesis. Brandeis University.

Chairetakis , A., (1991). The Past in the Present: Community Variation and Earthquake Recovery in the Sele Valley, Southern Italy, 1980-1989. Unpublished Ph.D. thesis presented to Columbia University.

Drabek, T.E., (1986). Human System Responses to Disaster: An Inventory of Sociological Findings. New York: Springer Verlag.

Ersoy Ş., (2013). 2013 AFET RAPORU "Dünya ve Türkiye, Yıldız Teknik Üniversitesi, Doğa Bilimleri Araştırma Merkezi.

Faas A.J. and Barrios R.E. (2015). Applied Anthropology of Risk, Hazards, and Disasters. Human Organization: Winter 2015, Vol. 74, No. 4, pp. 287-295.

Fagan B.M.. (2005). Atlas of Anthropology, Published in Upper Saddle River (N.J.) by Pearson education

Gould SJ., (1998). Sex, Drugs, Disasters, and the Extinction of Dinosaurs (Ed. Michael Alan Park, Biological Anthropology), Mayfield Publishing Company, Toronto.

Haque, C., and Zaman M.., (1993). "Human Responses To Riverine Hazards in Bangladesh: a Proposal for Sustainable Development." World Development 21: 93-107.

Kadıŏlu, M., (2008). Modern, Bütünleşik Afet Yönetimin Temel İlkeleri, Afet Zararlarını Azaltmanın Temel İlkeleri (Editörler: Prof.Dr.Mikdat Kadığlu, Doç.Dr. Emin Özdamar), JICA Türkiye Ofisi, Yayın No:2, sayfa 1-34.

Lindstrom L., (1993). Cargo Cult: Strange Stories of Desire from Melanesia and Beyond. Honolulu: University of Hawaii Press.

Maida, C., (1996). Crisis and Compassion in a World of Strangers. New Brunswick: Rutgers University Press.

Oliver Smith A.,(1996). Anthropological Research on Hazards and Disasters, Annual Review of Anthropology, Vol. 25., pp. 303-328.

Özey, R., (2006). Afetler Coğrafyası, Aktif Yayınevi, İstanbul.

Torry, W., (1979). "Anthropological studies in Hazardous Environments: Past Trends and New Horizons." Current Anthropology 20: 517-541.

Zaman, M.,(1989). “The Social and Political Context of Adjustment to Riverbank Erosion Hazard and Population Resettlement in Bangladesh." Human Organization 48: 196-205 